\title{
Formação continuada e prática profissional do enfermeiro
} na área de urgência: avaliação do curso "Manobras Avançadas de Suporte ao Trauma e Emergências Clínicas - MAST"

Inservice education and professional nursing practice in the emergency care area: evaluation of the course on "Advanced Procedures in the Care of Trauma and Clinical Emergency Patients"

A mudança do perfil epidemiológico ocorrida no final do século $X X$ trouxe uma emergente preocupação para a Saúde Pública. Os dados alarmantes de mortes em adultos jovens por causas externas têm motivado o investimento por parte de órgãos governamentais, visando a diminuir a morbimortalidade por essas causas, reconhecidas como conseqüência da violência. Por outro lado, tem sido apontada a deficiência dos cursos de graduação em Enfermagem na formação do profissional para atuar na área de Urgência. Visando a minimizar este problema e recuperar o papel do profissional de Enfermagem dentro de uma abordagem científica e humanista, um grupo de enfermeiros implementou, em 1994, uma proposta de formação continuada para profissionais de Enfermagem consubstanciada no curso "Manobras Avançadas de Suporte ao Trauma e Emergências Clínicas - MAST". O objetivo do presente trabalho foi realizar uma avaliação do referido curso, a partir das representações das instituições contratantes $e$ de enfermeiros formados durante o período de 1999 a 2001. Caracterizado como um estudo descritivo, exploratório, foi fundamentado nos pressupostos da Avaliação de Orientação Subjetiva Interpretativa, proposta por Aoki (apud Grego, 1997), e da Pesquisa Avaliativa, proposta por Contandriopoulos et al. (1992), no que se refere à pertinência do programa, mediante a análise estratégica, e ao processo de formação e suas possíveis repercussões, mediante a análise da intervenção. $A$ pertinência do programa foi justificada pelas motivações políticas e técnicas que levaram as instituições a contratarem o MAST. Na análise de intervenção avaliamos aspectos da organização do curso e suas repercussões na prática do enfermeiro na organização do setor, respondendo às motivações políticas, $e$ na qualidade de assistência, respondendo às motivações técnicas. Resultados obtidos poderão subsidiar o aperfeiçoamento da prática do enfermeiro na área de Urgência, a exigir um profissional dinâmico, crítico $e$ qualificado cientificamente. Poderão, ainda, contribuir para a melhoria da qualidade do atendimento às vítimas de violência de forma integral, como preconiza o Sistema único de Saúde (SUS). Ao mesmo tempo, trazer novos elementos para o aperfeiçoamento da proposta do MAST e para a discussão da práxis integrada e articulada da Enfermagem, uma profissão ainda em construção, que busca redefinir seu papel na promoção da Saúde, em particular na área de Urgência.

Carla Pedrosa Marega Luciano Gomes Dissertação de Mestrado, 2002 Curso de Pós-Graduação em Saúde Coletiva Faculdade de Medicina, Universidade Estadual Paulista, UNESP/Botucatu <rudyolg@unimedmarilia.com.br>

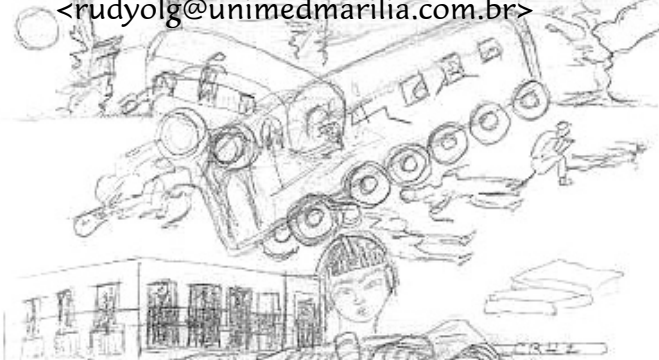

PALAVRAS-CHAVE: Saúde Rública; violência, urgência, Enfermagem; formação continuada; avaliação de programa. KEYWORDS: Public Health; violence; emergencies; Nursing; inservice education; program evaluation.

PALABRAS CLAVE: Salud Pública; violencia, urgencia; Enfermería; formación continuada; evaluación de programa.

Recebido para publicação em: 12/12/02 Aprovado para publicação em: 06/01/03 
TESES

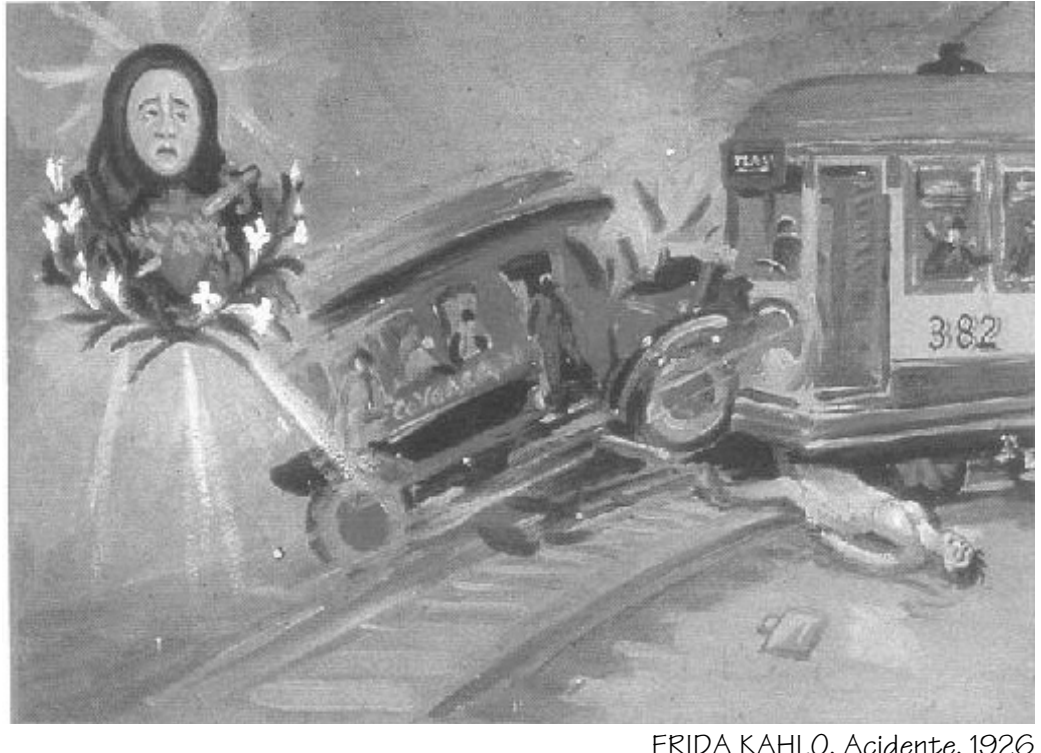

174 Interface - Comunic, Saúde, Educ, v7, n12, p.171-4, fev 2003 